Tropical Journal of Pharmaceutical Research June 2016; 15 (6): 1183-1189

ISSN: $1596-5996$ (print); 1596-9827 (electronic) (C) Pharmacotherapy Group, Faculty of Pharmacy, University of Benin, Benin City, 300001 Nigeria. All rights reserved.

\title{
Protective effect of (-)-epigallocatechin gallate on ultraviolet $b$-induced skin damage in hairless mice
}

\author{
Chang Liu ${ }^{1}$, Xin-Qiang Zheng ${ }^{1}$, Li-Ping Xiang ${ }^{2}$, Jian-Liang Lu ${ }^{1}$, Curt Anthony \\ Polito ${ }^{1}$ and Yue-Rong Liang ${ }^{1 *}$
}

${ }^{1}$ Zhejiang University Tea Research Institute, Hangzhou 310058, ${ }^{2}$ Guizhou Tea and Tea Products Quality Supervision and Inspection Center, Zunyi 563100, PR China

*For correspondence: Email: yrliang@zju.edu.cn; Tel/Fax: +86 57188982704

Received: 17 February 2016

Revised accepted: 19 May 2016

\begin{abstract}
Purpose: To investigate the protective effect of green tea (-)-epigallocatechin gallate (EGCg) on ultraviolet $B$ (UV-B)-induced skin damages in hairless mice in order to develop a natural sunscreen compound for use in skin care products and cosmetics.

Methods: EGCg was dissolved in acetone at concentrations of $1.0,10.0$ and $50.0 \mathrm{mg} / \mathrm{mL}$, and topically applied to the skin of hairless mice at doses of $0.2 \mathrm{~mL} / \mathrm{cm}^{2}$, with acetone as control. The mice were then irradiated by $100 \mu \mathrm{W} / \mathrm{cm}^{2}$ UV-B for $30 \mathrm{~min}$ daily. EGCg treatment and UV-B irradiation were carried out daily for 28 consecutive days. The mice were then sacrificed and their dorsal skin examined by transmission electron microscopy (TEM) on the 28th day.

Results: UV-B irradiation induced severe macroscopic skin damage including chapping, cracking and abnormal desquamation in the treated hairless mice. EGCg showed dose-dependent protective effects against UV-B induced damage on the skin. Treatments with 10.0 and $50.0 \mathrm{mg} / \mathrm{mL}$ EGCg alleviated UV$B$-induced skin damage by suppressing both keratinocyte apoptosis and mitochondrial dysfunction, along with inhibiting the production of melanin pigment.

Conclusion: Topical application of green tea EGCg shows dose-dependent protective effect against UV-B-induced damage on hairless mouse skin. Thus, the plant compound can potentially be used as an alternative agent for photoprotection against UV-B exposure.
\end{abstract}

Keywords: UV-B, Green tea EGCg, Photoprotection, Stratum corneum, Mitochondrion, Melanosome

Tropical Journal of Pharmaceutical Research is indexed by Science Citation Index (SciSearch), Scopus, International Pharmaceutical Abstract, Chemical Abstracts, Embase, Index Copernicus, EBSCO, African Index Medicus, JournalSeek, Journal Citation Reports/Science Edition, Directory of Open Access Journals (DOAJ), African Journal Online, Bioline International, Open-J-Gate and Pharmacy Abstracts

\section{INTRODUCTION}

Skin is an organ of the integumentary system, made up of multiple layers of ectodermal tissue, which serves as a protective barrier over the body's surface. The occurrence of many skin diseases such as skin tumors and skin aging are considered to be related to excessive exposure to ultraviolet B (UV-B) light, usually from exposure to sunlight. UV-B is a form of electromagnetic radiation with a wavelength ranging from $280 \mathrm{~nm}$ to $320 \mathrm{~nm}$ [1]. UV-B triggers generation of cyclobutane pyrimidine dimers (CPDs) and some photoproducts, which cause DNA damage and mutation in the epidermal cells, resulting in carcinogenesis [2].

Although epidemiological studies claim that application of sun screen lotion is helpful for skin protection, sun screen lotion may be inadequate for preventing all UV related skin damages. Due to their antioxidant properties, botanical substances, such as (-)-epigallocatechin-3gallate $(E G C g)$ in green tea, are considered to be 
promising natural materials for preventing skin from UV related damage and have attracted a lot of recent research attention. Phenolic compounds are reported to possess antiradiation properties because of their antioxidant and anti-inflammatory properties [3].

EGCg, a major polyphenolic constituent in green tea, is an effective free radical scavenger [3]. EGCg has been shown to inhibit UV-A-induced melanogenesis via suppression of both tyrosinase (TRY) activity and melanosome maturation, and it is an effective melanogenesis inhibitor [4]. Topical application of EGCg in hydrophilic cream has also showed high protection of photocarcinogenesis in UV-Bradiated $\mathrm{SKH}-1$ hairless mouse model [5]. There are results from clinical studies showing that EGCg treatment reduced the occurrence of tumors in different organs including skin, liver, lungs, breast, stomach and prostate [6]. A formulation containing tannase-converted green tea extract is effective in inhibiting UV-B-induced oxidative damage and in protecting skin from UVB photodamage [7].

Previous studies involving mechanisms of EGCg acting on UV-B induced damages were usually investigated in cell culture systems. Tests using $\mathrm{HaCaT}$ cells concluded that green tea polyphenols afforded protection against UV-B induced stress by interacting with UV-B induced reactive oxygen species (ROS) and attenuating mitochondrion-mediated apoptosis [8]. However, these mechanisms need to be evaluated and verified in animal models and/or clinical studies $[7,9]$.

The present study was designed to investigate the photoprotective effect of EGCg on UV-Binduced skin damages in hairless mice by using acetone as a vehicle solvent for delivering EGCg. Ultrastructural changes in the skin tissues induced by UV-B were observed by transmission electron microscopy (TEM).

\section{EXPERIMENTAL}

\section{Animals}

Forty-two hairless mice (21 males and 21 females) were purchased from the Shanghai Laboratory Animal Center, Chinese Academy Sciences (Shanghai, China). The mice were housed in an animal facility and acclimatized for one week under conditions at $27 \pm 1{ }^{\circ} \mathrm{C}, 35 \pm 5$ $\%$ humidity, $12 \mathrm{~h}$ light/12 $\mathrm{h}$ dark cycle, free access to water and a normal caloric standard diet.

The experimental procedures involving animals and their care were conducted in conformity with the Guide for Care and Use of Laboratory Animals Published by the US National Institutes of Health (NIH publication no. 85 - 23, 1996). Ethical approval for the animal studies was issued by the Ethics Committee for Animal Experimentation of the Shanghai Laboratory Animal Center, Chinese Academy Sciences (Shanghai, China), with the approval ref. no. SCXK (Hu)-2012-0005.

\section{Treatment}

Before beginning the study, the mice were randomly divided into 6 groups: Blank Control (BC, with no EGCg or UV-B irradiation treatments); Negative Control (NC, receiving topical application of vehicle solvent (acetone) and UV-B irradiation); Positive Control (PC, receiving topical application of KIEHL'S ultra light daily UV defense (SPF50 PA+++) and UV-B irradiation); Low Level EGCg Treatment (LL, receiving topical application of $1.0 \mathrm{mg} / \mathrm{mL} E G C g$ dissolved in acetone and UV-B irradiation); Medium Level EGCg Treatment (ML, receiving topical application of $10.0 \mathrm{mg} / \mathrm{mL} \quad \mathrm{EGCg}$ dissolved in acetone and UV-B irradiation); and High Level EGCg Treatment $(\mathrm{HL}$, receiving topical application of $50.0 \mathrm{mg} / \mathrm{mL} \quad \mathrm{EGCg}$ dissolved in acetone and UV-B irradiation).

For each EGCg treatment, the EGCg acetone solutions were topically applied to the skin of the hairless mice at measured dosages of 10 $\mu \mathrm{L} / \mathrm{cm}^{2}$. $30 \mathrm{~min}$ later, the mice were exposed to $30 \mathrm{~min}$ of UV-B irradiation $\left(100 \mu \mathrm{W} / \mathrm{cm}^{2}\right)$. UV-B radiation was supplied by six (6) UV-B lamps (Spectronics BLE-1T158 Tube, 15 watt). Each EGCg treatment and UV-B irradiation were carried out daily for consecutive 28 days. Then, on the 28th day, the mice were killed and their dorsal skins were sampled for transmission electronic microscopy (TEM) examination.

\section{Transmission electron microscopy (TEM)}

\section{Sample fixation}

The skin tissue samples were preliminarily fixed with $2.5 \%(\mathrm{w} / \mathrm{v})$ glutaraldehyde in phosphate buffer ( $\mathrm{pH} 7.0)$ for $4 \mathrm{~h}$, and then washed three times using phosphate buffer $(\mathrm{pH}$ 7.0). The preliminary fixed samples were finally fixed in 1 $\%(w / v) \mathrm{OsO}_{4}$ dissolved in phosphate buffer $(\mathrm{pH}$ 7.0) for $1 \mathrm{~h}$ and then washed three times in phosphate buffer ( $\mathrm{pH} 7.0)$. 


\section{Dehydration}

The fixed skin samples were dehydrated in an increasing concentration series of ethanol (30\%, $50 \%, 70 \%, 80 \%, 90 \%, 95 \%$ and $100 \%$, v/v), lasting for $20 \mathrm{~min}$ at each concentration level.

\section{Infiltration}

The dehydrated skin samples were placed in a mixture of acetone and Spurr resin ERL-4206 $(1: 1)$ for $1 \mathrm{~h}$ at room temperature, then were transferred into a mixture of acetone and Spurr resin ERL-4206 (1:3) for $3 \mathrm{~h}$, and finally transferred into pure Spurr resin overnight.

\section{Embedding and ultrathin sectioning}

The above fixed skin samples were placed in capsules containing embedding medium (Spurr resin ERL-4206) at $70{ }^{\circ} \mathrm{C}$ for $9 \mathrm{~h}$. Sections with thickness $70-90 \mathrm{~nm}$ were made on a ReichertJung OM U2 ultra-microtome (Reichert-Jung Co., Heidelburg, Germany) and were stained using uranyl acetate and alkaline lead citrate for $15 \mathrm{~min}$ [8]. The sections were examined and photographed with a Hitachi transmission electronic microscope (Hitachi Model H-7650, Hitachi Ltd., Tokyo, Japan).

\section{Statistical analysis}

One-way analysis of variance followed by Tukey's multiple comparisons test was performed using the scientific statistic software SPSS (version 20.0). $P=0.05$ was considered statistically significant for differences between treatments.

\section{RESULTS}

\section{Effect of EGCg on morphological characteristics of stratum corneum}

Over the course of the UV-B treatments, the dorsal skins of the hairless mice were affected, wrinkling after the first week, peeling and finally signs of spiloplaxia. Moreover, there were obvious differences in morphological characteristics of stratum corneum among the six treatment groups (Figure 1). In the negative control group, UV-B exposure induced severe macroscopic skin damage such as chapping, cracking and abnormal desquamation (Figure 1, NC). Topical application of UV defense agent (KIEHL'S ultra light daily UV defense (SPF50 PA+++)) showed good protective effect on the hairless mice skin exposed to UV-B irradiation (Figure 1, PC).

The protective effects of EGCg was dosedependent. Low level EGCG treatment (1.0 $\mathrm{mg} / \mathrm{mL}$ ) showed little protective effect on the skin (Fig 1, LL). However, treatments of medium (10.0 $\mathrm{mg} / \mathrm{mL})$ and high $(50.0 \mathrm{mg} / \mathrm{mL})$ levels of $E G C g$ produced protective effects similar to that of the positive control group (Figure 1, PC, ML and HL). These results suggest that EGCg produces protective effects on the skins of hairless mice exposed to UV-B radiation in a dose dependent manner.

\section{Effect of EGCg on ultra-structure of epidermis}

Differences in the thickness of the stratum corneum layer of the skins were recognized based on the type of treatment (Figure 2, Table 1).

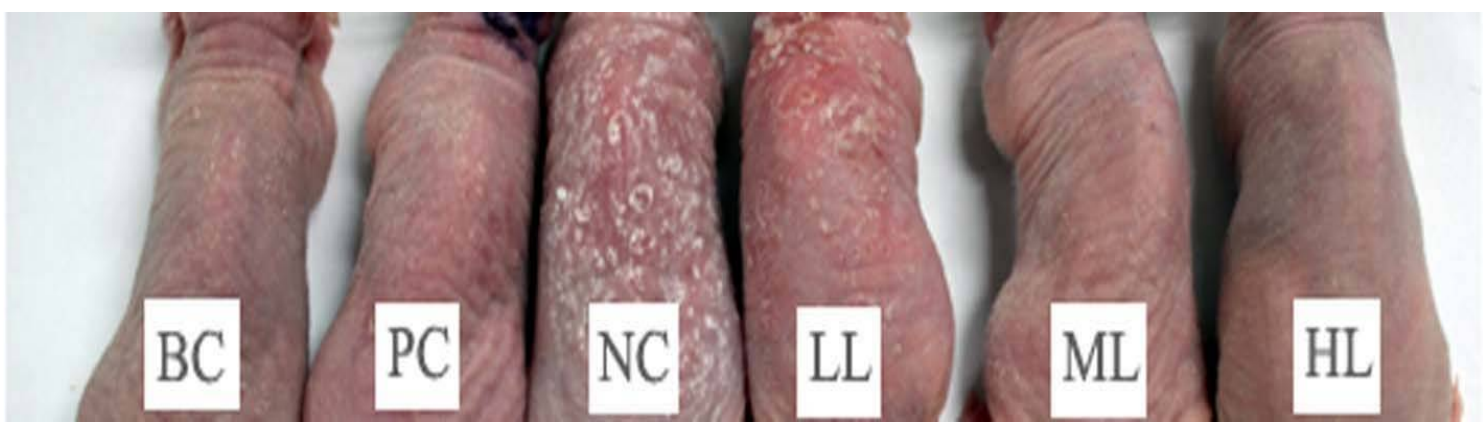

Figure 1: Effect of UV-B and EGCg on skin aging of hairless mice. BC: blank control, neither EGCg nor UV-B irradiation; PC: positive control, receiving topical application of KIEHL'S ultra light daily UV defense (SPF50 PA+++) and UV-B irradiation; NC: negative control, receiving topical application of vehicle solvent (acetone) and UV-B irradiation; LL: low level EGCg treatment, receiving topical application of $1.0 \mathrm{mg} / \mathrm{mL}$ EGCg dissolved in acetone and UV-B irradiation; ML: medium level EGCg treatment, receiving topical application of $10.0 \mathrm{mg} / \mathrm{mL} E G C g$ dissolved in acetone and UV-B irradiation; HL: high level EGCg treatment, receiving topical application of $50.0 \mathrm{mg} / \mathrm{mL} \mathrm{EGCg}$ dissolved in acetone and UV-B irradiation 
After 28 days of UV-B irradiation, the stratum corneum thickness was increased most in the skins of the negative control group while increasing least in the positive and high level EGCg treatment groups. The positive control group was most effective at preventing stratum corneum incrassation. Low level EGCg (1.0 $\mathrm{mg} / \mathrm{mL}$ ) had no protective effect on the statum corneum, while medium and high levels of EGCg (10.0 and $50.0 \mathrm{mg} / \mathrm{mL}$ ) significantly inhibited the stratum corneum incrassation induced by UV-B irradiation (Table 1).

In the blank control without UV-B irradiation, few melanosomes, in which pigment melanin precipitated, were observed (Figure 2, CB). However, there were many melanosomes in the UV-B irradiated treatments (Figure 2, NC, PC, $\mathrm{LL}, \mathrm{ML}, \mathrm{HL}$ ). These results suggest that UV-B stimulated the production of pigment melanin. The positive control with UV defense agent and treatment with high level EGCg $(\mathrm{HL})$ had less melanosomes than the negative control (NC) and treatments with low level $(\mathrm{LL})$ and high level $(\mathrm{HL})$ EGCg (Figure 2), suggesting that high level EGCg and the UV defense agent suppressed the production of pigment melanin induced by UV-B irradiation.

Figure 3 shows that obvious degenerations were observed in mitochondria of negative control (Figure 3, NC) and low level EGCg $(1 \mathrm{mg} / \mathrm{ml})$ (Figure 3, LL), in which mitochondrial crest and matrix density were reduced, and vacuolation was observed. However, there were no significant differences in mitochondrial structures between treatments of medium and high levels of $\mathrm{EGCg}$ (Figure 3, ML \& $\mathrm{HL}$ ), blank control (Figure 3, BC) and positive control (Figure3, PC), in which mitochondrial membrane and mitochondrial matrix were clearly observed. These results indicate that an appropriate concentration of $\mathrm{EGCg}$ protected skin damages in hairless mice irradiated by UV-B through its protective effect on mitochondria.

Table 1: Stratum corneum thickness of various treatments ${ }^{a}$ (mean $\pm \mathrm{SD}, \mu \mathrm{m}^{\mathrm{b}}$ )

\begin{tabular}{llllll}
\hline BC & NC & PC & LL & ML & HL \\
\hline & $4.65 \pm 0.1$ & $20.88 \pm 3.4$ & $21.38 \pm 0.2$ & $12.62 \pm 0.12$ & $4.85 \pm 0.3$ \\
$4.27 \pm 0.07 \mathrm{~A}$ & $0 \mathrm{~A}$ & $8 \mathrm{~B}$ & $2 \mathrm{C}$ & $\mathrm{D}$ & $1 \mathrm{~A}$ \\
\hline
\end{tabular}

${ }^{a}$ : The group labels are the same as in Figure $1{ }^{\text {b }}:$ Mean values followed different capital letters were significantly different at $p<0.05$
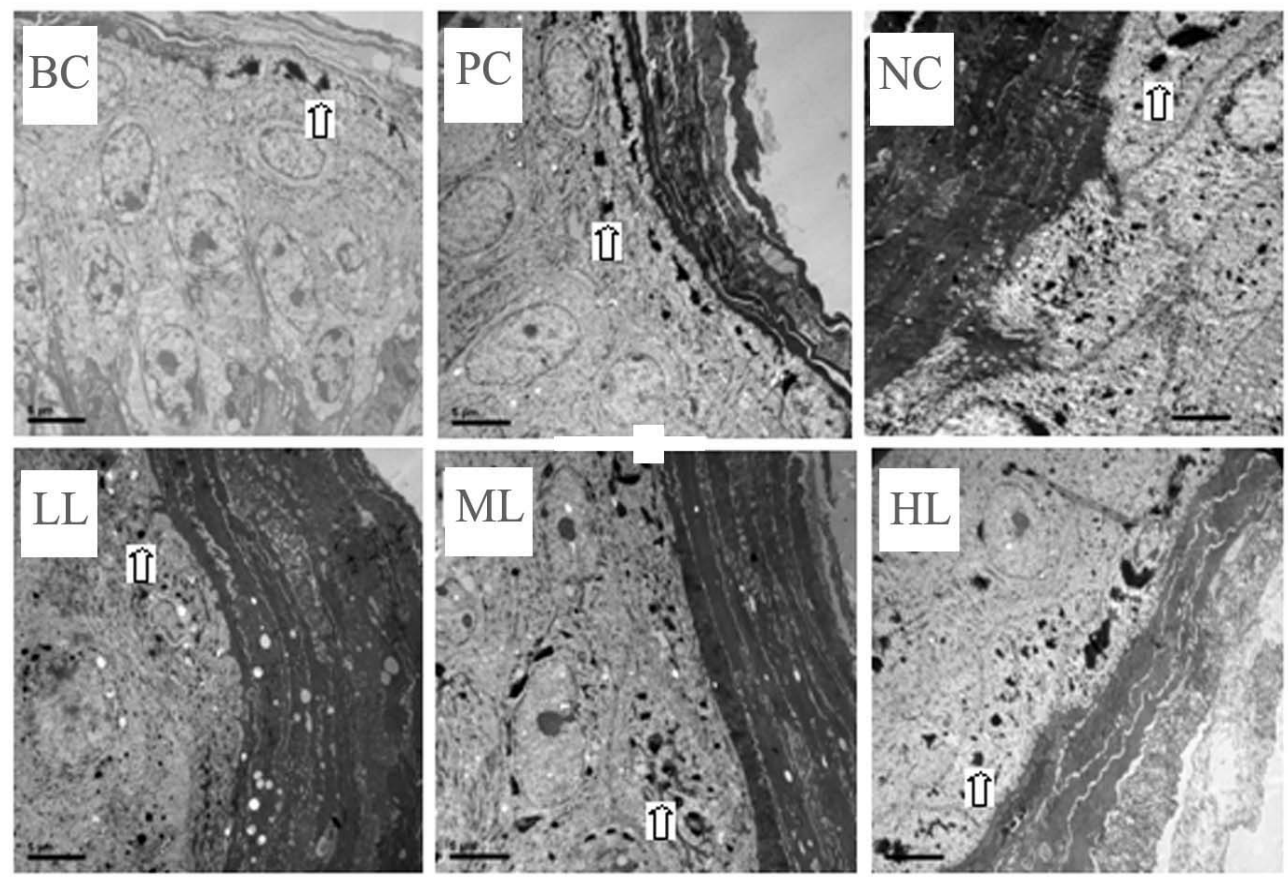

Figure 2: Effect of UV-B and EGCg on ultra-structure of epidermis. The group labels are the same as in Figure 1; arrows denote melanosomes 

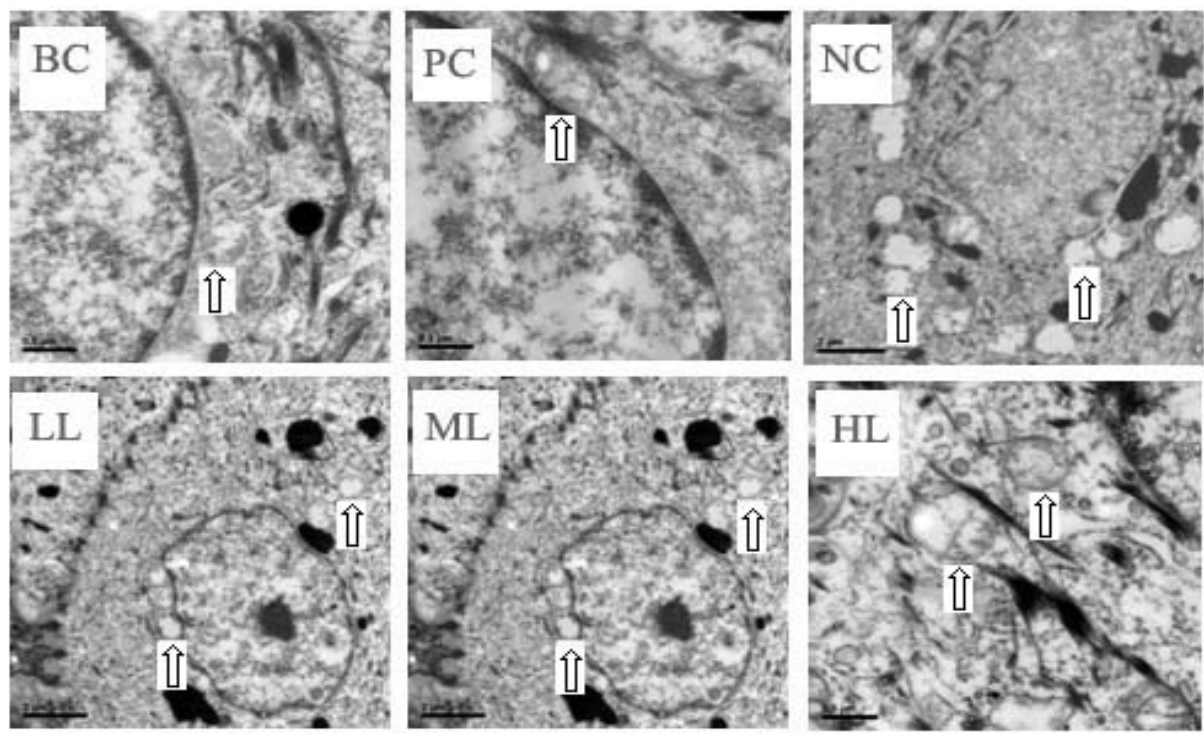

Figure 3: Effect of UV-B and EGCg on mitochondria. The group labels are the same as in Figure 1; arrows denote mitochondria

\section{DISCUSSION}

Cutaneous aging is a complex biological phenomenon commonly embodied in wrinkling, sagging and increased laxity. Although intrinsic skin aging is considered to be genetically determined, cumulative exposure to sunlight contributes to and exacerbates a majority of the skin's 'aging' [10]. For example, skin exposed to sunlight or UV rays becomes rough with wrinkles and irregular pigmentation and morphological characteristics. An increase in matrix metalloproteinase (MMP) activity and a decrease in expression of collagen type I protein are considered to be responses of skin to UV stress, which leads to massive elastosis and collagen degeneration [11]. Research suggests that MMP1 (one of MMP enzymes) is the major enzyme responsible for digestion of collagen type I protein in UV-irradiated skin [12]. Tissue inhibitor of metalloproteinase (TIMPs) and inhibitors of MMPs play a major role in the maintenance of extracellular matrix homeostasis [13]. Sen et al treated MDA-MB-231 cells with $20 \mu \mathrm{mol} / \mathrm{L} \mathrm{EGCg}$ for $48 \mathrm{~h}$, and the expression of TIMP-1 increased 32 -fold compared to the untreated control set, which indicates that EGCg enhanced the expression of TIMP-1, along with the reduction in mRNA expression and activity of MMP-9 [14]. The present study showed that EGCg had protective effects on the UV-B damaged skins of hairless mice. It can be concluded that $\mathrm{EGCg}$ stimulated the expression of TIMP-1 and inhibited the expression of MMP-1, which played a role in the maintenance of extracellular matrix homeostasis.
The present TEM study revealed that medium and high levels of EGCg (10 and $50 \mathrm{mg} / \mathrm{mL}$ ) significantly inhibited the incrassation of stratum corneum induced by UV-B irradiation. Corneocytes, composing most of the stratum corneum, are terminally differentiated keratinocytes. Intensive irradiation of UV-B injured the keratinocytes (which form the proliferative layer of the epidermis) resulting in an obvious increase in the amount of dead keratinocytes and thickening of the stratum corneum [15]. The intercellular lipids in stratum corneum play an important role in maintaining the barrier properties of the skin. The increase of stratum corneum lipids, along with the decrease in epidermal permeability, was a response of the epidermis to UV-B irradiation [16].

Mitochondrion, one of the most prominent and important organelles in eukaryotic cells, provides energy from metabolic fuels through oxidative phosphorylation [17]. It is the cell's powerhouse. In response to UV-B irradiation, there was a marked increase in the number of melanosomes [1]. The present study showed that EGCg suppressed the formation of melanosomes in a dose-dependent manner, suggesting that high levels of EGCg alleviated skin browning induced by UV-B. EGCg tea catechins exhibited sunscreen properties that alleviated UV-B stress [18]. It is clear that melanogenesis induced by UV radiation is characterized by proliferation and differentiation of functioning melanocytes. There is research indicating that tyrosine-kinase p59Fyn is a crucial factor influencing dedifferentiation and transformation of melanocytes. The expression of tyrosine-kinase 
P59Fyn leads to down-regulation of mitogenactivated protein kinase phosphatase 1 (MKP-1) and suppression of the differentiation of melanocytes [19]. There was also an in vitro study which indicated that EGCg inhibited the activity of tyrosine-kinase P59Fyn, resulting in suppression of melanocyte cell transformation [20]. The tyrosine-kinase p59Fyn is considered to be a target of EGCg [19]. The suppressive effects of $E G C g$ on the formation of melanosomes is thought to be related to its regulation effect on the expression of tyrosinekinase p59Fyn.

It has been reported that UV-B irradiation altered the structures and functions of mitochondria. Excessive exposure to UV-B induced formation of reactive oxygen species (ROS), which led to changes in mitochondrial size and internal cristae (also known as mitochondrial-mediated apoptosis) [8]. It is hypothesized that ROS activates permeability transition pore opening, leading to mitochondrial swelling. This in turn induces the release of cytochrome $\mathrm{c}$ from cardiolipin and outer membrane rupture via proapoptotic protein translocation [21]. The present TEM study showed that medium and high levels of EGCg prevented mitochondria from vacuolization and degeneration induced by UV-B irradiation. It is considered that the $\mathrm{EGCg}$ afforded protection against the UVB-induced stress via both interacting with UVB-induced reactive oxygen species and attenuating mitochondrion-mediated apoptosis.

\section{CONCLUSION}

The findings of this present study show that topical application of green tea EGCg protects the skin of hairless mice from UV-B-induced damages in two ways, viz, by suppressing both mitochondrial dysfunction, and by inhibiting keratinocyte apoptosis. Therefore, EGCg is a potential alternative agent for photoprotection against UV-B irradiation.

\section{ACKNOWLEDGEMENT}

This work was financially supported by National Key Technology R\&D Program in 12th Five Year Plan of China (Project no. 2012BAD36B06-2).

\section{DECLARATIONS}

\section{Conflict of Interest}

No conflict of interest associated with this work.

\section{Contribution of Authors}

The authors declare that this work was done by the authors named in this article and all liabilities pertaining to claims relating to the content of this article will be borne by them.

\section{REFERENCES}

1. Ichihashi $M$, Ueda $M$, Budiyanto A, Bito T, Oka $M$, Fukunagam M, Tsuru K, Horikawa T. UV-induced skin damage. Toxicology 2003; 15: 21-39.

2. Hidema J, Taguchi T, Ono T, Teranishi M, Yamamoto $K$, Kumagai $T$. Increase in CPD photolyase activity functions effectively to prevent growth inhibition caused by UVB radiation. Plant J 2007; 50: 70-79.

3. Luo $X Y, L i N N$, Liang YR. Effects of Ilex latifolia and Camellia sinensis on cholesterol and circulating immune complexes in rats fed with a high-cholesterol diet. Phytother Res 2013; 27: 62-65.

4. Liang YR, Kang SY, Deng L, Xiang LP, Zheng XQ. Inhibitory effects of (-)-epigallocatechin-3-gallate on melanogenesis in ultraviolet A-induced B16 murine melanoma cell. Trop J Pharm Res 2014; 13: 1825-1831.

5. Mittal A, Piyathilake C, Hara Y, Katiyar SK. Exceptionally high protection of photocarcinogenesis by topical application of (-)-epigallocatechin-3-gallate in hydrophilic cream in SKH-1 hairless mouse model relationship to inhibition of UVB-induced global DNA hypomethylation. Neoplasia 2003; 5: 555-565.

6. Mukhtar H, Ahmad N. Tea polyphenols: prevention of cancer and optimizing health. Am J Clin Nutr 2000; 71: 1698-1703.

7. Hong YH, Jung EY, Shin KS, Kim TY, Yu KW, Chang UJ, Suh HJ. Photoprotective effects of a formulation containing tannase-converted green tea extract against UVB-induced oxidative stress in hairless mice. Appl Biochem Biotech 2012; 166: 165-175.

8. Wu LY, Zheng $X Q, L u J L$, Liang YR. Protective effect of green tea polyphenols against ultraviolet B-induced damage to HaCaT cells. Hum Cell 2009; 22: 18-24.

9. Li NN, Deng L, Xiang LP, Liang YR. Photoprotective effect of tea and its extracts against ultraviolet radiationinduced skin disorders. Trop J Pharm Res 2014; 13: 475-483.

10. Kang JS, Park IH, Cho JS, Hon SM, Kim TH, Lee SH, Lee HM. Epigallocatechin-3-gallate inhibits collagen production of nasal polyp-derived fibroblasts. Phytother Res 2014; 28: 98-103.

11. Jenkins G. Molecular mechanisms of skin aging. Mech Ageing Dev 2002; 123: 801-810.

12. Dong KK, Damaghi N, Picart SD, Markova NG, Obayashi K, Okano Y, Masaki H, Grether-Beck S, Krutmann J, Smiles KA, Yarosh DB. UV-induced DNA damage initiates release of MMP-1 in human skin. Exp Dermatol 2008; 17: 1037-1044.

13. Bhuvarahamurthy $V$, Kristiansen $G O$, Johannsen $M$, Loening SA, Schnorr D, Jung K, Staack A. In situ gene

Trop J Pharm Res, June 2016; 15(6): 1188 
expression and localization of metalloproteinases MMP1, MMP2, MMP3, MMP9, and their inhibitors TIMP1 and TIMP2 in human renal cell carcinoma. Oncol Rep 2006; 15: 1379-1384.

14. Sen T, Dutta A, Chatterjee A. Epigallocatechin-3-gallate (EGCG) downregulates gelatinase- $B$ (MMP-9) by involvement of FAKJERKJNFkappaB and $A P-1$ in the human breast cancer cell line MDA-MB-231. Anti-cancer Drug 2010; 21: 632-644.

15. Kim JE, Kim BJ, Jeong MS, Seo SJ, Kim MN, Hong CK, Ro $B$ I. Expression and modulation of II-37 in normal human keratinocytes, HaCaT cells, and inflammatory skin diseases. J Korean Med Sci 2005; 20: 649-654.

16. Shao JJ, Jie YC, Zhen FL, Jie Y, Dun FC, Xiao JZ. Biophysical and morphological changes in the stratum corneum lipids induced by UVB irradiation. J Dermatol Sci 2006; 44: 29-36.

17. Hatefi $Y$. The mitochondrial electron transport chain and oxidative phosphorylation system. Annu Rev Biochem 1985; 54: 1015-1069.
18. Lee $X Z$, Liang $Y R$, Chen $H$, Lu JL, Liang HL, Huang FP, Mamati EG. Alleviation of UV-B stress in Arabidopsis using tea catechins. Afr J Biotechnol 2008; 7: 41114115.

19. Wellbrock C, Weisser C, Geissinger E, Troppmair J, Schart M. Activation of p59 (Fyn) leads to melanocyte dedifferentiation by influencing MKP-1-regulated mitogen-activated protein kinase signaling. J Biol Chem 2002; 277: 6443-6454.

20. He Z, Tang F, Ermakova S, Li M, Zhao Q, Cho YY, Ma WY, Choi HS, Bode AM, Yang CS, Dong Z. Fyn is a novel target of (-)-epigallocatechin gallate in the inhibition of JB6 $\mathrm{Cl} 41$ cell transformation. Mol Carcinogen 2008; 47: 172-183.

21. Hervouet E, Simonnet $H$, Godinot C. Mitochondria and reactive oxygen species in renal cancer. Biochimie 2007; 89: 1080-1088. 